\title{
PENERAPAN TEKNOLOGI WEB SERVICE PADA SISTEM INFORMASI DATA REKAM MEDIS RUMAH SAKIT XYZ
}

\author{
Triawan Adi Cahyanto ${ }^{1)}$ \\ ${ }^{1)}$ Program Studi Teknik Informatika, Fakultas Teknik, Universitas Muhammadiyah Jember \\ Email: ${ }^{1}$ triawanac@unmuhjember.ac.id
}

\begin{abstract}
Data processing system of inpatient medical records is one of the functions of the administration in providing services to patients to meet the demands, both for the management of the hospital, patients, and paramedics. Hospitals located in small urban areas are generally still doing manual processing (simple still be processing data in the handwritten form printed in report form archives). Based on these problems, we need solutions to make medical record information system using web services technology. Web service technology is used to synchronize data between the subunits in the hospital. Systems built using services more than one database that can be accessed via WSDL service and the data format used is XML. Services available for access are data search services and data detail services.
\end{abstract}

Keyword: Information System, Medical Records, Web Service

\section{PENDAHULUAN}

Sistem pengolahan data rekam medis pasien rawat inap merupakan salah satu fungsi dari kegiatan administrasi dalam memberikan pelayanan terhadap pasien untuk memenuhi tuntutan, baik untuk pihak manajemen rumah sakit, pasien maupun untuk paramedis [1]. Data rekam medis pasien merupakan data yang berisi catatan dan dokumen tentang identitas pasien, pemeriksaan, pengobatan, tindakan dan pelayanan lain kepada pasien pada fasilitas pelayanan kesehatan [2]. Data rekam medis merupakan data yang bersifat pribadi, oleh karena itu, data rekam medis harus dikelola dengan bijak. Mengingat sifat data rekam medis pasien adalah pribadi dan sensitif, maka penelitian ini tidak menggunakan data asli pasien, melainkan hanya menggunakan data ujicoba "random". Rumah sakit yang terdapat di wilayah kota kecil umumnya masih melakukan pengolahan data secara manual (sederhananya masih berupa pengolahan data dalam bentuk tulisan tangan yang dicetak dalam bentuk laporan arsip) [3]. Berdasarkan permasalahan tersebut, maka dibutuhkan solusi untuk membuat sistem informasi data rekam medis pasien menggunakan teknologi web service. Teknologi web service digunakan untuk melakukan sinkronisasi data antar sub-sub unit yang ada di rumah sakit maupun untuk menghubungkan basis data dari beberapa rumah sakit yang berbeda jikalau antar rumah sakit menghendaki[4]-[7]. Teknologi web service yang digunakan adalah $N u S O A P$. NuSOAP merupakan library sederhana yang dibuat dengan bahasa pemrograman PHP [8].

\section{Metode Penelitian}

Metode penelitian merupakan langkah-langkah yang berisi tahapan dalam menyelesaikan permasalahan dari penelitian yang dikerjakan. Adapun tahapan penelitian pada penelitian ini adalah

\subsection{Definisi Kebutuhan}

Pada tahap ini dilakukan proses penggalian kebutuhan dari aplikasi yang dibangun. Proses penggalian kebutuhan dilakukan dengan cara mencari referensi terkait dengan data rekam medis pasien dalam bentuk sampel yang diperoleh melalui internet.

\subsection{Pemodelan Sistem}

Setelah proses definisi terhadap kebutuhan aplikasi dilakukan selanjutnya dilakukan pembuatan pemodelan sistem. Pemodelan sistem merupakan suatu gambaran model dan cara kerja sistem informasi data rekam medis [9]. Sistem informasi data rekam medis dimodelkan dengan dua metode yaitu menggunakan DFD (Data Flow Diagram) dan ERD (Entity Relationship Diagram). DFD menggambarkan model desain proses bisnis yang terjadi pada sistem yang dibangun. Sedangkan ERD menggambarkan model rancangan basis data dari sistem informasi data rekam medis.

\subsection{Data Flow Diagram (DFD)}

Berikut ini merupakan gambaran proses bisnis dari sistem informasi data rekam medis pasien yang dirancang sesuai dengan analisa kebutuhan.

\subsubsection{Diagram Konteks (DFD Level 0)}

Merupakan gambaran umum dari sistem informasi data rekam medis pasien.

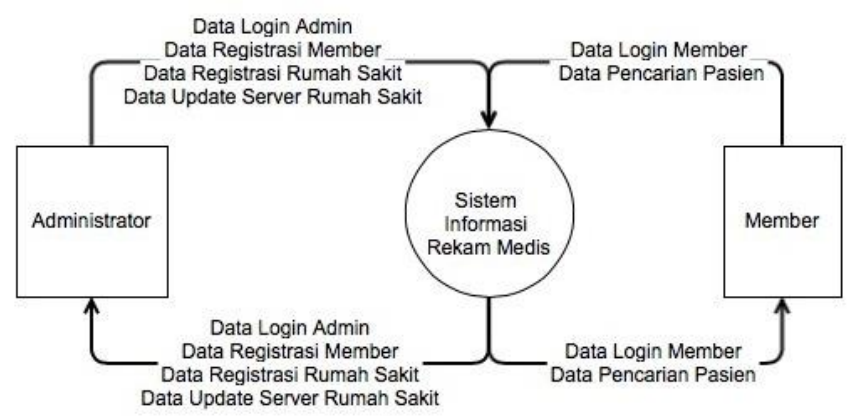

Gambar 1. Diagram Konteks Sistem Informasi Data Rekam Medis Pasien

Gambar 1 merupakan gambar diagram konteks dari sistem yang dibuat. Berdasarkan gambar 1 tersebut, sistem yang dibuat terdiri dari dua entitas, yaitu:

\section{- Administrator}

Merupakan hak akses yang diberikan kepada pengguna dengan status admin. Pengguna yang mempunyai status sebagai admin akan mempunyai layanan yaitu masuk sistem 
sebagai admin, sehingga nanti mempunyai beberapa layanan yaitu dapat mengolah data registrasi pengguna baru (member) dan dapat mengolah data registrasi rumah sakit (pendataan lokasi server rumah sakit).

\section{- Member}

Merupakan hak akses yang diberikan kepada pengguna dengan status member. Pengguna yang mempunyai status sebagai member dapat mengakses beberapa layanan, diantaranya: masuk sebagai member, sehingga nanti dapat mengakses layanan pencarian data pasien.

\subsubsection{DFD Level 1}

DFD level 1 menggambarkan proses yang terjadi pada sistem informasi data rekam medis pasien secara keseluruhan. Gambar 2 berikut ini menjelaskan aliran data yang terdapat pada sistem informasi data rekam medis pasien.

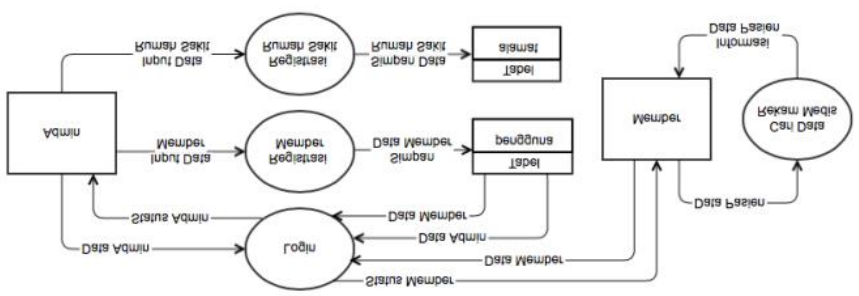

Gambar 2. DFD Level 1 Sistem Informasi Data Rekam Medis Pasien

Pada gambar DFD level 1 tersebut, terdapat beberapa proses yang terjadi, yaitu:

- Login

Proses login diwajibkan bagi semua pengguna sistem. Hal ini dimaksudkan untuk meminimalisir ancaman dari pengguna yang tidak berhak mengakses sistem.

\section{- Register Member}

Proses register member digunakan untuk menambah member baru, dalam hal ini yaitu pasien rumah sakit. Apabila sudah terdaftar ke dalam sistem, maka member tersebut dapat mengakses daftar riwayat medis pasien dari rumah sakit yang terdaftar. Pasien dapat mencari data rekam medis yang berasal dari rumah sakit yang sudah terdaftar dan tergabung dengan sistem.

\section{- Register Rumah Sakit}

Proses register rumah sakit digunakan untuk menambah data lokasi server rumah sakit yang baru. Apabila ada rumah sakit yang tertarik menggunakan layanan web service ini, dapat menambahkan lokasi url dari service yang dapat digunakan, sehingga layanan pencarian data rekam medis rumah sakit tersebut dapat diakses dengan mudah dan terdistribusi.

\subsection{ERD (Entity Relationship Diagram)}

Merupakan suatu model untuk menjelaskan hubungan antar data dalam basis data berdasarkan objek-objek dasar data yang mempunyai hubungan antar relasi [10]. ERD untuk memodelkan struktur data dan hubungan antar data untuk menggambarkannya digunakan beberapa notasi dan simbol.
$E R D$ pada sistem informasi data rekam medis pasien adalah sebagai berikut:
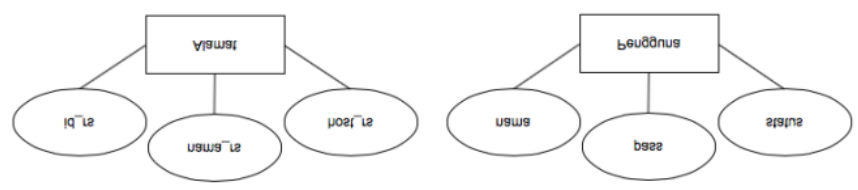

Gambar 3. ERD Sistem Informasi Data Rekam Medis Pasien

\subsection{Desain Tabel Basis Data}

Sistem informasi data rekam medis pasien mempunyai dua tabel yang terdapat pada basis data yang digunakan agar dapat mendukung berjalannya sistem. Tabel tersebut berada di dalam satu database yang sama yaitu "medikClient". Komposisi dan struktur tabel yang menyusun basis data dari sistem informasi data rekam medis pasien adalah sebagai berikut:

\section{- Tabel Alamat}

Tabel alamat berisi data-data alamat url dari rumah sakit yang akan didaftarkan ke dalam sistem informasi data rekam medis pasien berbasis web service ini. Desain tabel alamatnya adalah sebagai berikut:

Tabel 1 Desain Tabel Alamat

\begin{tabular}{|l|l|l|}
\hline Nama Kolom & Tipe Data & Constraint \\
\hline Id & $\operatorname{Int}(11)$ & Primary Key \\
\hline nama_rs & $\operatorname{Varchar}(255)$ & \\
\hline url_rs & Varchar(255) & \\
\hline
\end{tabular}

\section{- Tabel Pengguna}

Tabel pengguna berisi data pengguna yang dapat masuk ke dalam sistem. Pengguna memiliki dua status yaitu admin dan member. Berikut ini merupakan desain tabel pengguna:

Tabel 2 Desain Tabel Pengguna

\begin{tabular}{|l|l|l|}
\hline Nama Kolom & Tipe Data & Constraint \\
\hline Nama & Varchar (255) & \\
\hline Pass & Varchar (255) & \\
\hline Status & Varchar (11) & \\
\hline
\end{tabular}

\subsection{Testing dan Implementasi Aplikasi}

Dalam tahap ini dilakukan uji coba terhadap aplikasi yang telah dibuat. Software akan diuji untuk diketahui bugs atau error. Uji coba akan dilakukan dengan beberapa data tes.

\subsection{Perawatan Perangkat Lunak}

Tahap perawatan perangkat lunak merupakan tahap akhir dari proses penelitian ini. Dimana pada tahap ini dilakukan perbaikan terhadap kesalahan atau error di dalam aplikasi beserta proses maintenance dari suatu aplikasi. 


\section{HASIL DAN PEMBAHASAN}

Berdasarkan tahapan penelitian yang terdapat pada metode penelitian, berikut ini merupakan penjelasan fitur pada sistem informasi data rekam medis pasien dengan teknologi web service.

\subsection{Halaman Administrator}

Halaman ini berisi menu dan fitur yang hanya dapat diakses oleh pengguna dengan status "admin" sehingga dapat mengakses fitur tertentu yang terdapat pada sistem. Berikut ini merupakan tampilan halaman administrator.

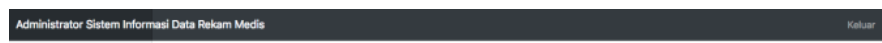

Sattar ruman save $\quad$ Selamat datang "admin" ini adalah halaman administrator

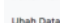

Gambar 4. Tampilan Halaman Administrator

Fitur yang terdapat pada halaman administrator adalah

\section{- Pendaftaran Pengguna}

Halaman ini merupakan halaman yang digunakan untuk menambah pengguna yang baru agar bisa menggunakan sistem. Tampilan halaman pendaftaran pengguna adalah

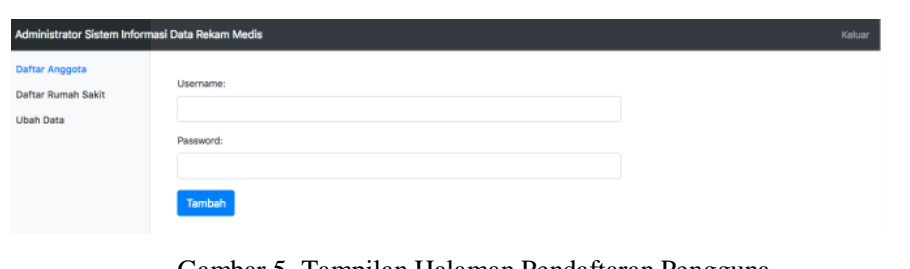

- Pendaftaran Rumah Sakit

Halaman ini digunakan untuk menambah data rumah sakit yang baru, sehingga ketika pengguna sistem ingin mengakses data rumah sakit, maka pengguna sistem dapat mencari data dari berbagai rumah sakit yang terdaftar ke sistem. Tampilan halaman pendaftaran rumah sakit adalah

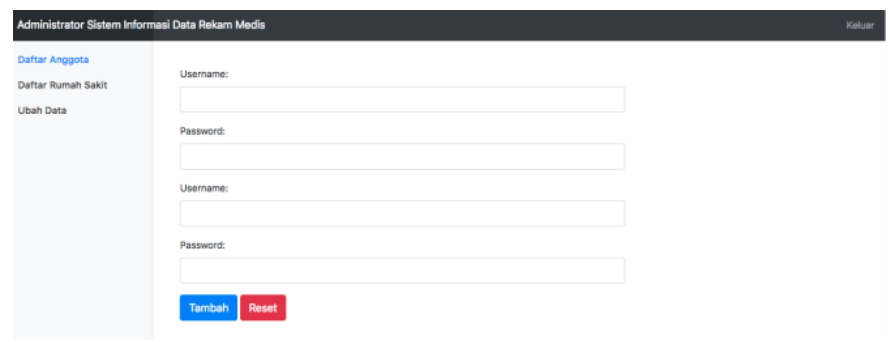

Gambar 6. Halaman Pendaftaran Rumah Sakit

- Perubahan data

Halaman perubahan data digunakan untuk mengubah dan menghapus data rumah sakit yang terdapat pada sistem. Tampilan halaman perubahan data adalah

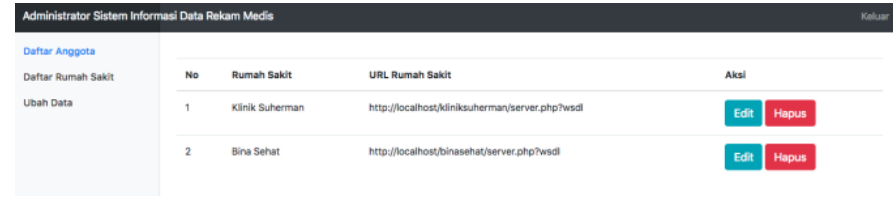

Gambar 7. Halaman Perubahan Data Rumah Saki

\section{- Keluar Sistem}

Halaman keluar digunakan oleh pengguna sistem untuk keluar dari sistem.

\subsection{Halaman Pengguna}

Halaman pengguna merupakan menu atau fitur yang dapat diakses oleh pengguna dengan status "member". Menu dan fitur yang dapat diakses adalah lokasi rumah sakit, kategori perawatan, dan nama pasien. Tampilan halaman pengguna adalah

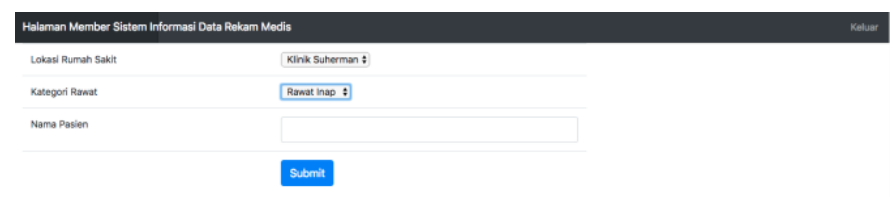

Gambar 8. Halaman Pengguna Sistem Selain Administrator

\subsection{NuSOAP Sebagai Teknologi Web Service}

Teknologi web service yang digunakan adalah NuSOAP library berbasis bahasa pemrograman PHP. NuSOAP mendukung bahasa pemrograman PHP versi 5.6 sampai versi saat ini. Teknologi web services digunakan sebagai layanan dalam mengakses data menggunakan layanan wsdl (web services description language) sedangkan format data yang dikirim dalam bentuk xml (extensible markup language).

Penggunaan web service dibagi menjadi dua model, yaitu web service client, dan web service server. Web service client merupakan sistem yang dibuat untuk melakukan pengaturan layanan sehingga client dapat mengakses layanan yang diberikan. Layanan yang dimaksud pada penelitian ini adalah basis data data rekam medis dari dua contoh basis data pada rumah sakit $x y z$. Contoh konfigurasi layanan terdapat pada gambar 7. Potongan kode sumber web service client adalah sebagai berikut: 


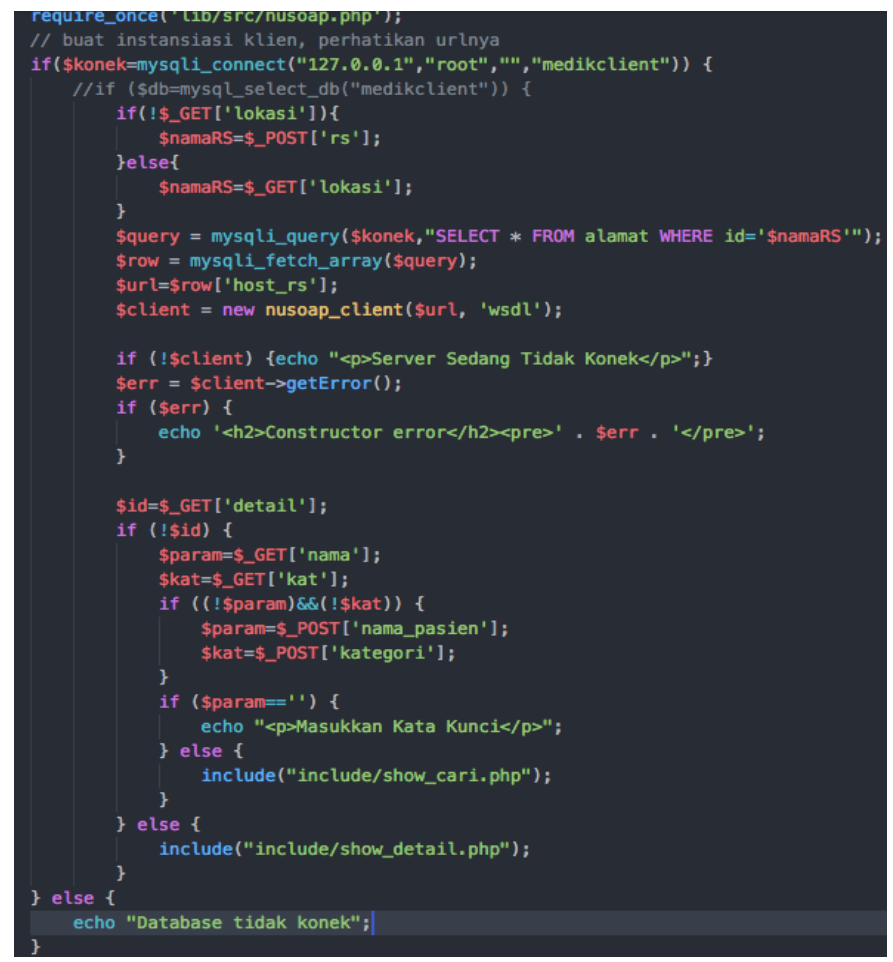

Gambar 9. Kode Sumber Web Service Client

Web service client dapat mengakses data jika terdapat layanan wsdl dari server yang sudah didaftarkan ke basis data sistem melalui url server.

Web service server merupakan sistem yang mempunyai layanan atau data. Data yang dimaksud adalah data rekam medis pasien. Web service server hanya menyediakan layanan, sehingga agar dapat diintegrasikan dengan layanan lain, maka harus digabungkan atau dikonfigurasi di web server client.

Penerapan web service server dapat dilihat pada layanan $w s d l$ dan format data $x m l$ yang bisa dilihat pada browser.

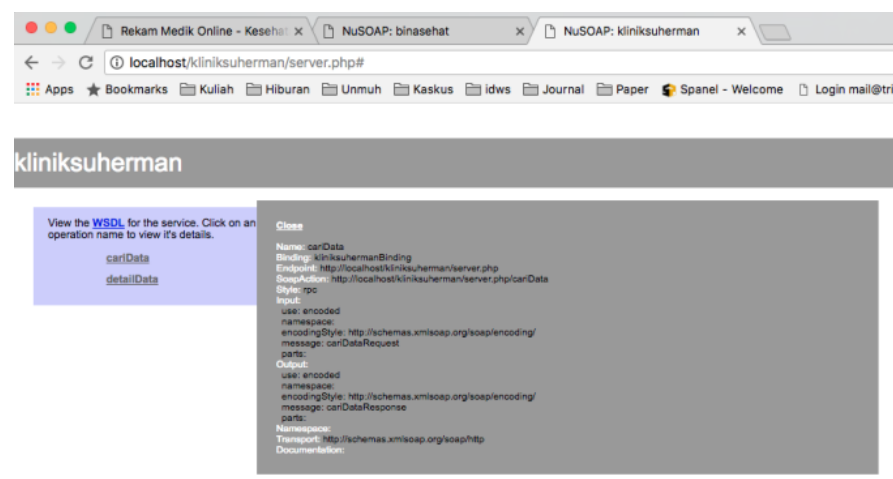

Gambar 10. WSDL dan XML Web Service Server

\section{KESIMPULAN DAN SARAN}

\section{A. Kesimpulan}

Berdasarkan paparan yang telah ditulis, dapat disimpulkan sebagai berikut:

- Rancangan sistem informasi data rekam medis pasien dengan teknologi web service dibuat untuk mencari data pasien rekam medis berdasarkan parameter lokasi rumah sakit dan kategori rawat inap atau rawat jalan.

- Sistem informasi data rekam medis pasien dengan teknologi web service dapat menambahkan data lokasi rumah sakit, sehingga dengan penambahan data rumah sakit maka sistem ini memiliki beberapa basis data rumah sakit yang saling terhubung. Namun, data rekam medis pasien merupakan data yang bersifat pribadi, jadi penerapan terhadap integrasi data rekam medis pasien tidak diperbolehkan.

- Penelitian ini hanya fokus terhadap pembangunan sistem informasi data rekam medis pasien menggunakan teknologi web service, tidak ada data pasien rumah sakit yang digunakan. Data pasien yang digunakan adalah data ujicoba untuk mendukung kinerja sistem.

- Layanan yang diizinkan untuk diakses yaitu layanan cari data pasien dan detail data pasien. Layanan ini hanya dapat diakses ketika pengguna atau pasien tersebut sudah terdaftar di sistem informasi data rekam medis.

\section{B. Saran}

Saran yang dapat dituliskan oleh penulis, supaya dapat dikembangkan lagi oleh peneliti selanjutnya, diantaranya:

- Penggunaan wsdl untuk "service" terhadap layanan sudah bagus dan efektif, namun sumber daya ke depan akan digantikan dengan "API” karena implementasi di berbagai platform lebih mudah digunakan.

- Pemrograman native php yang digunakan pada sistem ini sangat rentan terhadap eksploitasi data. Sangat disarankan untuk mengobah model logika pemrograman. 


\section{UCAPAN TERIMA KASIH}

Saya ingin mengucapkan terima kasih kepada teman-teman kuliah di Program Studi Teknik Informatika UIN Sunan Kalijaga angkatan 2006 dan kepada civitas akademik Universitas Muhammadiyah Jember yang tidak dapat disebut satu per satu yang telah membantu menyelesaikan penelitian ini. Tulisan ini merupakan kenang-kenangan terakhir dari tugas kelompok mata kuliah Pemrograman Jaringan.

\section{DAFTAR PUSTAKA}

[1] A. N. Renny and P. Beni, "Sistem Informasi Rekam Medis," J. Manaj. Sist. Inform., vol. 1, no. 2, pp. 147158, 2016.

[2] PERMENKESRI, "Peraturan Menteri Kesehatan Republik Indonesia Nomor 55 Tahun 2013 Tentang Penyelenggaraan Pekerjaan Perekam Medis Dengan," Peratur. Menteri Kesehat. Nomor 55 Tahun 2013 tentang Penyelenggaraan Pekerj. Perekam Medis, 2013.

[3] N. Bahiyah, "Sistem Informasi Rekam Medis Rumah Sakit KIA PKU Muhammadiyah Kotagede," Universitas Islam Negeri Sunan Kalijaga, 2010.

[4] T. A. Cahyanto, "Implementasi Smart Router Berbasis OpenWRT Sebagai Media Untuk File Sharing dan Chatting Pada Laboratorium Terpadu Unmuh Jember," 2018.

[5] T. A. Cahyanto, "Analisis deteksi penyusupan pada jaringan komputer menggunakan snort (studi kasus pada Dinas Pariwisata Propinsi Daerah Istimewa Yogyakarta)," Yogyakarta, 2011.

[6] T. A. Cahyanto, H. Oktavianto, and A. W. Royan, "Analisis dan Implementasi Honeypot Menggunakan Dionaea Sebagai Penunjang Keamanan Jaringan," JUSTINDO (Jurnal Sist. dan Teknol. Inf. Indones., vol. 1, no. 2, pp. 86-92, May 2013.

[7] T. A. Cahyanto, V. Wahanggara, and D. Ramadana, "Analisis dan Deteksi Malware Menggunakan Metode Malware Analisis Dinamis dan Malware Analisis Statis," JUSTINDO, vol. 2, no. 1, pp. 19-30, 2017.

[8] "NuSOAP - SOAP Toolkit for PHP download | SourceForge.net." [Online]. Available: https://sourceforge.net/projects/nusoap/. [Accessed: 19-Feb-2018]

[9] E. Murdani, "Pengembangan Sistem Informasi Rekam Medis Rawat Jalan Untuk Mendukung Evaluasi Pelayanan Di RSU Bina Kasih Ambarawa," Universitas Diponegoro, 2007.

[10] A. Kristiawan, "Sistem Informasi Rekam Medis Pada Klinik Mitra Medika Semarang,” 2012. 